DOI: $10.32604 /$ EE.2022.014877

\title{
ARTICLE
}

\section{Fuzzy-TOPSIS Evaluation of Power Product-Service System: A Framework Driven by Big Data}

\author{
Xuchang Hu \\ School of Information Engineering, College of Science \& Technology Ningbo University, Cixi, 315300, China \\ ${ }^{*}$ Corresponding Author: Xuchang Hu. Email: kate30133@sina.com \\ Received: 04 November 2020 Accepted: 10 December 2020
}

\begin{abstract}
Power product-service system (power PSS), which combines industrial electric products with electric energy services, is an effective solution for power enterprises under the background of the rapid development of power systems. In the life cycle of power PSS, evaluation decision of power PSS alternatives is of great significance for subsequent implementation. To address the power PSS alternative evaluation problem, a power PSS evaluation framework is explored driven by the big data of stakeholder comments. Based on the multi-stakeholder comments of power PSS evaluation decision's influence factors, the index system is constructed through analyzing and summarizing the co-occurrence matrix and semantic network diagram of high-frequency words. To determine the fuzzy index value of power PSS alternative, the stakeholders' vague opinions expressed by trapezoidal fuzzy number are integrated by group decision method. Fuzzy concept is introduced into the classical Technique for Order Preference by Similarity to an Ideal Solution (TOPSIS) method and fuzzy-TOPSIS method is put forward by using the fuzzy index value. The improved TOPSIS is adopted to sequence the power PSS alternatives. The case of power PSS evaluation of six alternatives for a power enterprise shows that the explored framework is effective and can provide a feasible solution for power PSS alternative evaluation.
\end{abstract}

\section{KEYWORDS}

Power product-service system; big data; trapezoidal fuzzy number; fuzzy-TOPSIS

\section{Introduction}

After first appearing in the mid-1990s, the concept of product service system (PSS) is getting more and more attention. At the beginning of this century, the United Nations Environment Program (UNEP) reported on the important role of PSS in sustainable development. Then PSS became one of the topics widely studied and discussed by academics and industry in the world. By systematically integrating products and services, PSS provides users with product functions rather than physical products to meet user needs, thereby achieving value added and sustainability of production and consumption throughout the product life cycle [1,2]. With the rapid development of power systems, the future grid companies are not only suppliers of electricity, but also providers of energy product service systems, providing users with highquality power products services.

The service of power products, to a great extent, determines the position and value of power products in the market, which is the concentrated embodiment of the core competitiveness of power enterprises. With the 
increasingly fierce market competition, power services have broken through the traditional sense of power products subsidiary elements and become a key factor for enterprises to expand market space. Power products and services promote each other and complement each other. Through the support of network technology and infrastructure, the power product service system (power PSS) is formed in an integrated way [3-6]. Power PSS has been widely used in enterprises because it provides an overall solution including power products and services. However, due to the ambiguity and incompleteness of the requirements expressed by power customers, as well as the deviation of power PSS designers' understanding of customer requirements, a variety of alternatives are often produced in the design of power PSS. Evaluating and selecting the alternatives objectively and reasonably are of great practical significance to the subsequent and implementation stage of power PSS.

\section{Related Works}

Due to the lack of research on power PSS evaluation decision, we can learn from the study of PSS evaluation decision as follows. In recent years, a series of related researches have been carried out on PSS design scheme evaluation. Based on the classical fuzzy set and grey system theory, Alfian et al. [7] proposed a design scheme evaluation method based on multi-level comprehensive attribute indexes such as service quality, customer satisfaction and maintainability. Chou et al. [8] combined fuzzy comprehensive evaluation with classification algorithm, and proposed a fuzzy classification comprehensive evaluation model of product scheme, striving to make the evaluation model more practical and reliable. Xia et al. [9] established the evaluation index system of product performance, economy, safety, reliability and environmental adaptability, determined the weight value of attribute index by using analytic hierarchy process (AHP), and combined with Technique for Order Preference by Similarity to Ideal Solution (TOPSIS) for scheme evaluation and decision-making. Wang et al. [10] used fuzzy Delphi method to determine the attribute index weight of product service implementation process system, and combined with Fuzzy AHP and fuzzy TOPSIS model, the effective evaluation of design scheme was realized. Fang et al. [11] constructed a multi-attribute evaluation system for complex mechanical and electrical product system. After determining the attribute weight through rough set knowledge rules, the fuzzy uncertain language was used to synthesize the attribute values, so as to evaluate the design scheme. In order to fully express the intention of decision makers in the process of service evaluation, Chen et al. [12] established a mixed uncertainty index model with fuzziness and randomness, and proposed an information axiom scheme evaluation method under the mixed uncertainty conditions of system and design range of random and fuzzy variables respectively. In order to deal with fuzzy service indexes effectively, Zuo et al. [13] proposed an evaluation method combining information axiom and intuitionistic fuzzy sets, and compared the information quantity of schemes without considering the weight of decision-making indexes, and then determined the optimal product service system scheme.

In essence, the design scheme evaluation of power PSS is a group collaborative decision-making process with multi-attribute index under uncertain environment. At present, although some scholars have carried out in-depth research on this issue and have achieved phased results, they are inevitably biased in the treatment of some basic problems as follows. On one hand, the construction of the index system is mostly from the perspective of researchers' literature research or subjective judgment, and lack of mining social network and big data related to power PSS. The development of big data technology has a profound impact on social economy and governance mode [14-17]. In recent years, some scholars have applied network data mining methods to quality monitoring, government decision-making and other fields. Cai et al. [16] proposed that enterprises can obtain competitive intelligence by using network technology and data mining technology, thus providing valuable information for enterprise decision-making. Tijis et al. [14] proposed that mining valuable information from a large number of data is very important to improve 
enterprise profitability and customer satisfaction. These studies provide a reference for the construction of index system of power PSS evaluation by mining user review big data.

On the other hand, the traditional alternatives evaluation methods mainly include TOPSIS [18], VIKOR [19] and AHP [20]. Among these research, TOPSIS is a typical method for multi-attribute evaluation. In classical TOPSIS, object's closeness, which is calculated by Euclidean distances between the evaluation object and the two ideal points, is used as the basis of evaluation. However, the objects on the perpendicular bisector of two ideal points have the same closeness and cannot be distinguished by classical TOPSIS. Therefore, classical TOPSIS needs to be improved to evaluate the power PSS.

To solve the above problems, this paper is geared to the needs of the practical engineering problems in power PSS, proposes a big data driven framework of power PSS evaluation. The index system is constructed through mining user review big data, which are collected from the multi-stakeholder comments about the influence factors of power PSS evaluation. Then, the vague opinions of power PSS alternative's performance on evaluation index from multiple stakeholders are expressed by trapezoidal fuzzy number and integrated to calculate the fuzzy index value. Lastly, fuzzy index value is introduced into classical TOPSIS and a fuzzy-TOPSIS method is put forward, which is adopted to evaluate the power PSS alternatives and select the optimal one.

\section{Research Architecture}

The research architecture of the proposed big data driven framework of power PSS evaluation is shown in Fig. 1 which is divided into four layers.

The four layers of the research architecture are explained from down to up as follows:

1. Stakeholder layer. In this layer, multiple stakeholders are divided into several categories which include power PSS user, power PSS design engineer, power PSS entrepreneur, user demand analyst, social and environmental researcher, etc.

2. Data layer. On one hand, by web crawler tool the big data resource from the perspective of multiple stakeholders is collected from online discussion, forum topic, random investigation, telephone interview. On the other hand, the opinions of alternatives' performance on each index are collected which are represented in fuzzy number form by expert vague assessment.

3. Approach layer. The multi-perspective review big data is processed through word segmentation and concept processing to construct the index system. Then the index value of power PSS alternative is determined by the integration of multiple stakeholders' vague assessment opinions, which are expressed by fuzzy numbers. In the end, a fuzzy-TOPSIS method is put forward and adopted to evaluate the power PSS alternatives based on the index system.

4. Alternative layer. There are several feasible power PSS alternatives to be evaluated. Through power PSS evaluation, the optimal power PSS alternative will be selected, which is important for the later implementation of power PSS.

\section{Index System of Power PSS Evaluation}

Forum topic, online discussion and user comment are typical channels that include multi-stakeholder review big data. Web crawler is used for collecting these big data about power PSS evaluation [21-25]. Then, concept processing and word segmentation processing are implemented by text analysis and word frequency statistics is carried out. Absolutely, the words with no actual meaning or obvious direction should be deleted. As a result, 90 high-frequency words are screened. Top 10 of them are shown in Fig. 2. 


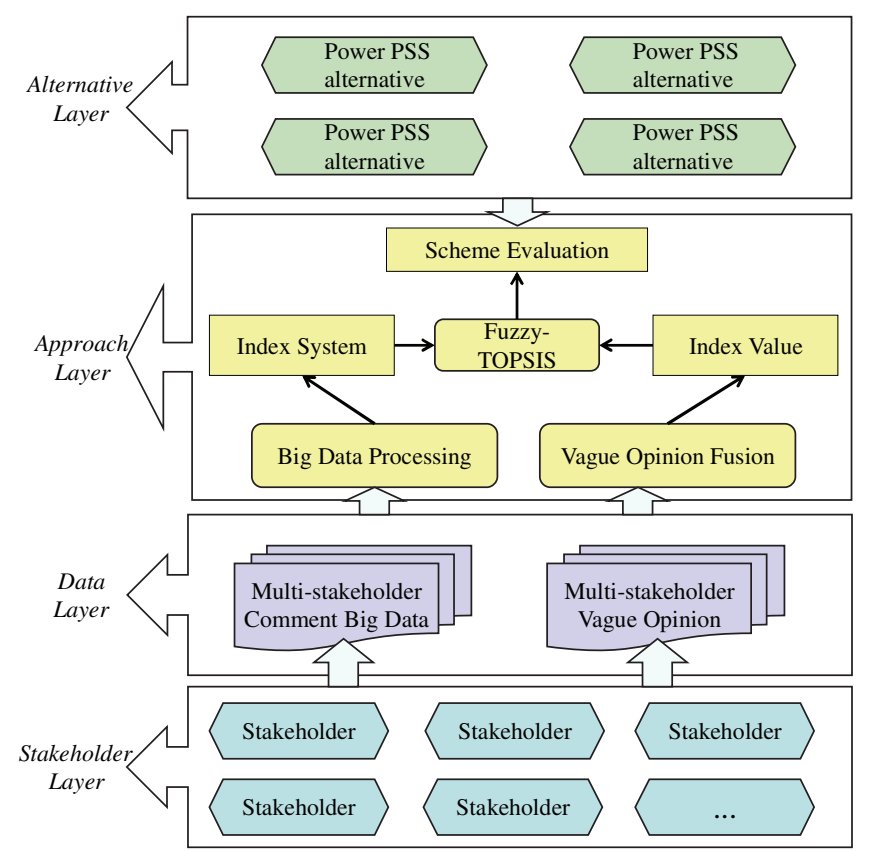

Figure 1: Research architecture of big data driven framework of power PSS evaluation

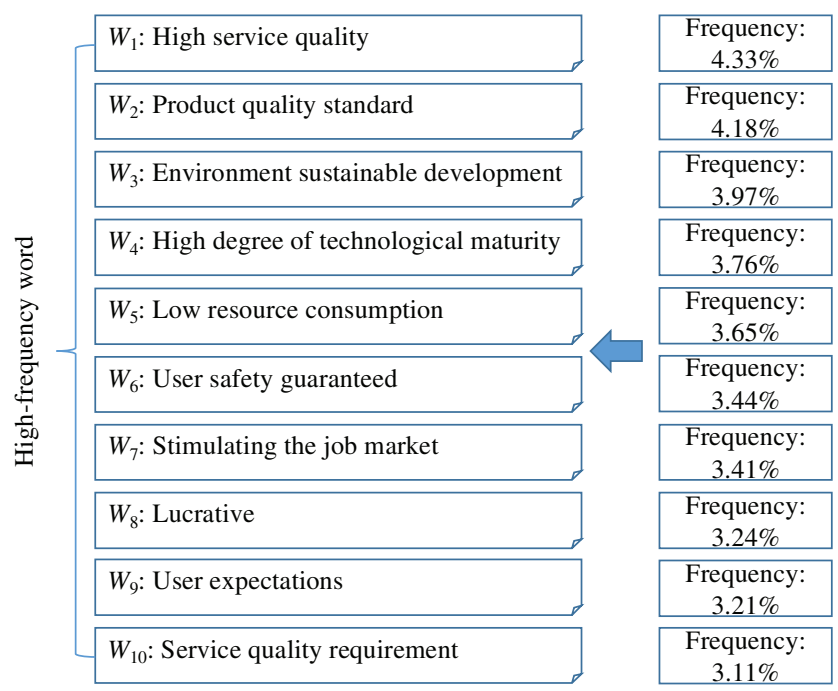

Figure 2: High-frequency words and their frequency (top 10)

In big data technology, the correlation relationship between two high-frequency words is expressed by co-occurrence matrix. If the value of the intersection of two high-frequency words is bigger, the correlation relationship between them is stronger.

Based on high-frequency word analysis, we obtain the co-occurrence matrix of high-frequency words. The co-occurrence matrix of top 10 high-frequency words is shown in Fig. 3. 
EE, 2022, vol.119, no.1

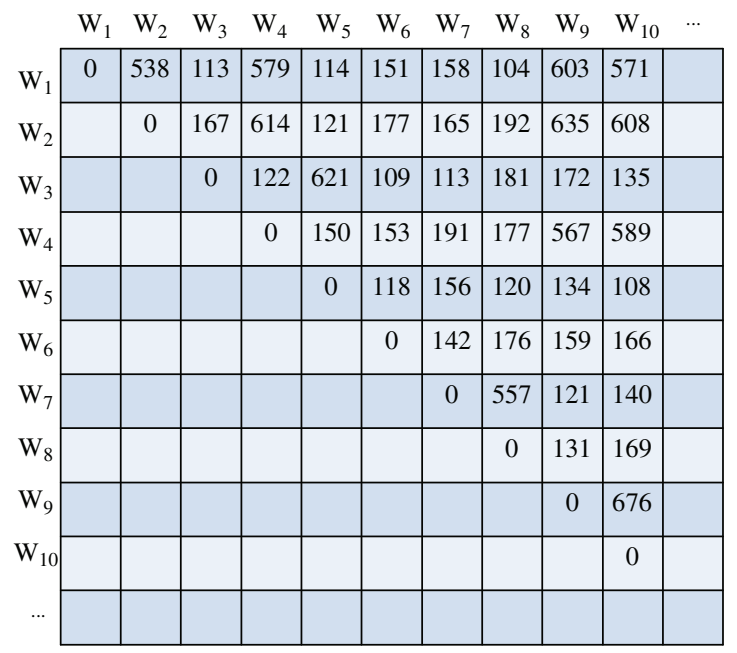

Figure 3: The matrix of co-occurrence times of top 10 high-frequency words

The semantic network diagram of top 30 high-frequency words, which is shown in Fig. 4, is obtained by social network analysis [22-25].

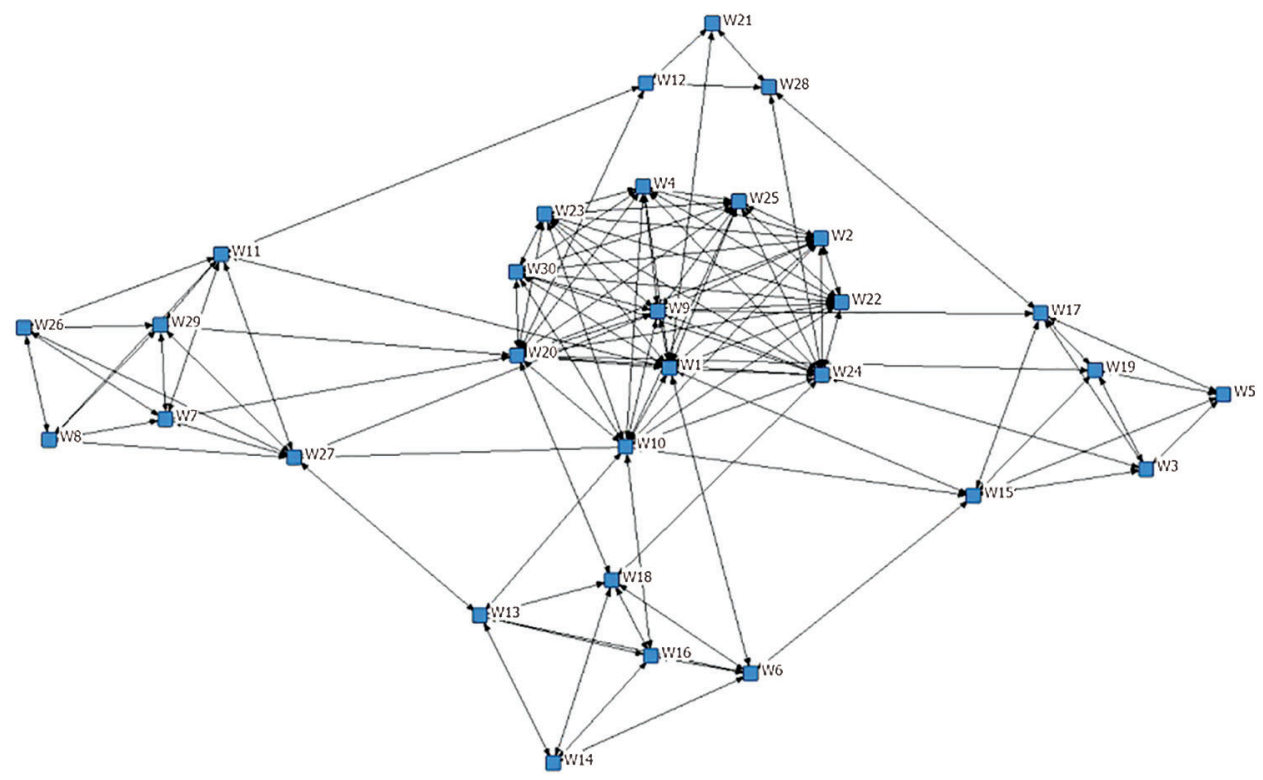

Figure 4: The semantic network diagram of top 30 high-frequency words

Through analysing the matrix of co-occurrence times of high-frequency words (Fig. 3) and the semantic network diagram of high-frequency words (Fig. 4), the text data of high-frequency words are abstracted. After that the high-frequency words with the same attribute are summarized and classified. At last, every high-frequency word is classified into a type, which is an index. The indexes $\left(I_{1}-I_{19}\right.$ in Fig. 5) can be aggregated ulteriorly into five attributes. The index system of power PSS evaluation decision is shown in Fig. 5. 




Figure 5: The index system of power PSS evaluation decision

\section{Index Value Determination}

Expert assessment method is usually used to determinate the index value of power PSS alternative. The performance of power PSS alternative on each index can be assessed by the stakeholders. However, the assessment opinion of stakeholder is always ambiguous and unclear. At this time, using exact number to represent the assessment opinion of stakeholder is unreasonable. In this paper, trapezoidal fuzzy number is chosen to replace exact number for the expression of assessment opinion of stakeholder [18]. Based on the arithmetic operation rules of trapezoid fuzzy number, the typical 9-scale assessment opinions and their exact values are converted into trapezoid fuzzy number as shown in Table 1.

It is assumed that $q$ experts (stakeholders) assess the performance of $p$ power PSS alternatives on every index. 
Table 1: Trapezoid fuzzy number corresponding to typical 9-scale assessment opinions and exact values

\begin{tabular}{lll}
\hline Trapezoid fuzzy number & \multicolumn{2}{c}{ Typical 9-scale assessment } \\
\cline { 2 - 3 } & Assessment opinion & Exact value \\
\hline$(4,17 / 3,9,9)$ & Best $\left(A O_{1}\right)$ & 9 \\
$(7 / 3,3,17 / 3,9)$ & Better $\left(A O_{2}\right)$ & 7 \\
$(3 / 2,13 / 7,3,4)$ & Little better $\left(A O_{3}\right)$ & 5 \\
$(1,11 / 9,13 / 7,7 / 3)$ & Good $\left(A O_{4}\right)$ & 3 \\
$(1,1,1,1)$ & Medium $\left(A O_{5}\right)$ & 1 \\
$(3 / 7,7 / 13,9 / 11,1)$ & Bad $\left(A O_{6}\right)$ & $1 / 3$ \\
$(1 / 4,1 / 3,7 / 13,3 / 2)$ & Litter worse $\left(A O_{7}\right)$ & $1 / 5$ \\
$(1 / 9,3 / 17,1 / 3,3 / 7)$ & Worse $\left(A O_{8}\right)$ & $1 / 7$ \\
$(1 / 9,1 / 9,3 / 17,1 / 4)$ & Worst $\left(A O_{9}\right)$ & $1 / 9$ \\
\hline
\end{tabular}

Stakeholder $r(1 \leq r \leq q)$ assesses the performance of alternative $s(1 \leq s \leq p)$ on index $I_{i}(1 \leq i \leq N)$ and $N=19)$ and the assessment result is one of the assessment opinions in Table 1 which is corresponding to trapezoid fuzzy number $\tilde{x}_{s, i}^{r}=\left(a_{s, i}^{r}, b_{s, i}^{r}, c_{s, i}^{r}, d_{s, i}^{r}\right)$. By aggregating the assessment opinions of all $q$ stakeholders, the group decision assessment value, which is also the index value of alternative $s(1 \leq s \leq p)$ on index $I_{i}$, is calculated as follows:

$\tilde{x}_{s, i}=\left(a_{s, i}, b_{s, i}, c_{s, i}, d_{s, i}\right)$

In Eq. (1), $a_{s, i}=\sum_{r=1}^{q} a_{s, i}^{r} / q, b_{s, i}=\sum_{r=1}^{q} b_{s, i}^{r} / q, c_{s, i}=\sum_{r=1}^{q} c_{s, i}^{r} / q, d_{s, i}=\sum_{r=1}^{q} d_{s, i}^{r} / q$.

After calculating the fuzzy index values of all power PSS alternatives on each index, the fuzzy index value matrix is obtained as $\tilde{X}=\left[\tilde{x}_{s, i}\right]_{p \times N}$ in which $\tilde{x}_{s, i}=\left(a_{s, i}, b_{s, i}, c_{s, i}, d_{s, i}\right)$.

\section{Power PSS Alternative Evaluation by Fuzzy-TOPSIS}

An improved TOPSIS by using fuzzy index value is put forward for power PSS alternative evaluation. The following is the detailed process of power PSS alternative evaluation by fuzzy-TOPSIS.

In fuzzy index value matrix $\tilde{X}=\left[\tilde{x}_{s, i}\right]_{p \times N}, \tilde{X}^{s}=\left[\tilde{x}_{s, 1}, \tilde{x}_{s, 2}, \ldots, \tilde{x}_{s, N}\right]$ represents power PSS alternative $s$. $\tilde{X}=\left[\tilde{x}_{s, i}\right]_{p \times N}$ can be divided into four sub-matrices as follows:

$A=\left[a_{s, i}\right]_{p \times N}$

$B=\left[b_{s, i}\right]_{p \times N}$

$C=\left[c_{s, i}\right]_{p \times N}$

$D=\left[d_{s, i}\right]_{p \times N}$

In sub-matrix $A=\left[a_{s, i}\right]_{p \times N}$, the positive ideal point and the negative ideal point are as follows:

$A^{+}=\left[a_{1}^{+}, a_{2}^{+}, \ldots, a_{i}^{+}, \ldots, a_{N}^{+}\right]$ 
$A^{-}=\left[a_{1}^{-}, a_{2}^{-}, \ldots, a_{i}^{-}, \ldots, a_{N}^{-}\right]$

In Eqs. (6) and (7), $a_{i}^{+}=\max \left\{a_{1, i}, a_{2, i}, \ldots, a_{p, i}\right\}$ and $a_{i}^{-}=\min \left\{a_{1, i}, a_{2, i}, \ldots, a_{p, i}\right\}$.

For $A^{s}=\left[a_{s, 1}, a_{s, 2}, \ldots, a_{s, N}\right]$, the distances from it to positive ideal point $A^{+}$and negative ideal point $A^{-}$are as follows:

$\operatorname{dis} A^{s,+}=\sqrt{\sum_{i=1}^{N}\left(a_{s, i}-a_{i}^{+}\right)^{2}}$

$\operatorname{dis} A^{S,-}=\sqrt{\sum_{i=1}^{N}\left(a_{s, i}-a_{i}^{-}\right)^{2}}$

Similarly, the distances from $B^{s}$ it to $B^{+}$and $B^{-}$are obtained as dis $B^{s,+}$ and dis $B^{s,-}$ respectively, the distances from $C^{s}$ it to $C^{+}$and $C^{-}$are obtained as dis $C^{s,+}$ and dis $C^{s,-}$ respectively, and the distances from $D^{s}$ it to $D^{+}$and $D^{-}$are obtained as dis $D^{s,+}$ and dis $D^{s,-}$ respectively. Here, $B^{s}=\left[b_{s, 1}, b_{s, 2}, \ldots, b_{s, N}\right]$, $C^{s}=\left[c_{s, 1}, c_{s, 2}, \ldots, c_{s, N}\right]$ and $D^{s}=\left[d_{s, 1}, d_{s, 2}, \ldots, d_{s, N}\right] ; B^{+}$and $B^{-}$are positive ideal point and the negative ideal point in sub-matrix $B=\left[b_{s, i}\right]_{p \times N}, C^{+}$and $C^{-}$are positive ideal point and the negative ideal point in sub-matrix $C=\left[c_{s, i}\right]_{p \times N}$, and $D^{+}$and $D^{-}$are positive ideal point and the negative ideal point in submatrix $D=\left[d_{s, i}\right]_{p \times N}$.

Therefore, the distances in trapezoid fuzzy number form from $\tilde{X}^{s}$ to positive ideal point and negative ideal point are obtained respectively as follows:

$\tilde{\delta}^{s,+}=\left(\operatorname{dis} A^{s,+}, \operatorname{dis} B^{s,+}, \operatorname{dis} C^{s,+}, \operatorname{dis} D^{s,+}\right)$

$\tilde{\delta}^{s,-}=\left(\operatorname{dis} A^{s,-}, \operatorname{dis} B^{s,-}, \operatorname{dis} C^{s,-}, \operatorname{dis} D^{s,-}\right)$

Then, through the gravity centre form transformation of trapezoid fuzzy number, $\tilde{\delta}^{s,+}$ and $\tilde{\delta}^{s,-}$ are converted into the real number form as follows:

$\delta^{s,+}=\frac{\left[\left(\operatorname{dis} C^{s,+}\right)^{2}+\left(\operatorname{dis} C^{s,+}\right)\left(\operatorname{dis} D^{s,+}\right)+\left(\operatorname{dis} D^{s,+}\right)^{2}\right]-\left[\left(\operatorname{dis} A^{s,+}\right)^{2}+\left(\operatorname{dis} A^{s,+}\right)\left(\operatorname{dis} B^{s,+}\right)+\left(\operatorname{dis} B^{s,+}\right)^{2}\right]}{3\left[\left(\operatorname{dis} C^{s,+}+\operatorname{dis} D^{s,+}\right)-\left(\operatorname{dis} A^{s,+}+\operatorname{dis} B^{s,+}\right)\right]}$

$\delta^{s,-}=\frac{\left[\left(\operatorname{dis} C^{s,-}\right)^{2}+\left(\operatorname{dis} C^{s,-}\right)\left(\operatorname{dis} D^{s,-}\right)+\left(\operatorname{dis} D^{s,-}\right)^{2}\right]-\left[\left(\operatorname{dis} A^{s,-}\right)^{2}+\left(\operatorname{dis} A^{s,-}\right)\left(\operatorname{dis} B^{s,-}\right)+\left(\operatorname{dis} B^{s,-}\right)^{2}\right]}{3\left[\left(\operatorname{dis} C^{s,-}+\operatorname{dis} D^{s,-}\right)-\left(\operatorname{dis} A^{s,-}+\operatorname{dis} B^{s,-}\right)\right]}$

At last, the closeness of power PSS alternative $s$ is obtained as follows:

$\phi^{s}=\frac{\delta^{s,-}}{\delta^{s,+}+\delta^{s,-}}$

According to the arranging rule of TOPSIS [18], all evaluation objects are arranged according to their closeness values. If a power PSS alternative has the biggest closeness value, it will be arranged at the first position. This means that it is the best alternative. Therefore, the power PSS alternative evaluation is achieved. 


\section{Case Study}

In order to promote the development of its power product and further enter the global market, improve product competitiveness and achieve sustainable development, a power enterprise construct its power PSS. In the design stage, several feasible power PSS alternatives are determined in the research and development process. These alternatives need to be evaluated to concentrate multiple resources to ensure the effective implementation of power PSS. There are six power PSS alternatives, which are P1-P6. They are evaluated according to the proposed framework as follows:

The stakeholder group (50 persons) consists of 10 power PSS users, 10 user demand analysts, 10 power PSS entrepreneurs, 10 social and environmental researchers and 10 power PSS design engineers. They carry out fuzzy assessment of the six power PSS alternatives, and use trapezoid fuzzy numbers to express their assessment opinions on the index value.

For example, to the performance of $\mathrm{P} 1$ on index $I_{1}, 3$ stakeholders thinks 'Best (AO1)', 1 stakeholder thinks 'Better (AO2)', 5 stakeholders think 'Little Better (AO3)', 17 stakeholders think 'Good (AO4)', 1 stakeholder thinks 'Medium (AO5)', 9 stakeholders think 'Bad (AO6)', 10 stakeholders think 'Litter worse (AO7)', 1 stakeholder thinks 'Worse (AO8)' and 3 stakeholders think 'Worst $(A O 9)$ '. The fuzzy comment statistics of P1 on all 19 indexes is shown in Table 2.

Table 2: The fuzzy comment statistics of P1

\begin{tabular}{llllllllll}
\hline & $\begin{array}{l}\text { Best } \\
(A O 1)\end{array}$ & $\begin{array}{l}\text { Better } \\
(A O 2)\end{array}$ & $\begin{array}{l}\text { Little better } \\
(A O 3)\end{array}$ & $\begin{array}{l}\text { Good } \\
(A O 4)\end{array}$ & $\begin{array}{l}\text { Medium } \\
(A O 5)\end{array}$ & $\begin{array}{l}\text { Bad } \\
(A O 6)\end{array}$ & $\begin{array}{l}\text { Litter worse } \\
(A O 7)\end{array}$ & $\begin{array}{l}\text { Worse } \\
(A O 8)\end{array}$ & $\begin{array}{l}\text { Worst } \\
(A O 9)\end{array}$ \\
\hline$I_{1}$ & 3 & 1 & 5 & 17 & 1 & 9 & 10 & 1 & 3 \\
$I_{2}$ & 20 & 2 & 1 & 7 & 6 & 0 & 6 & 0 & 8 \\
$I_{3}$ & 5 & 1 & 3 & 12 & 3 & 9 & 5 & 8 & 4 \\
$I_{4}$ & 7 & 5 & 4 & 3 & 5 & 1 & 7 & 2 & 16 \\
$I_{5}$ & 2 & 10 & 5 & 0 & 3 & 12 & 0 & 4 & 14 \\
$I_{6}$ & 1 & 8 & 3 & 2 & 4 & 1 & 14 & 0 & 17 \\
$I_{7}$ & 21 & 2 & 13 & 2 & 0 & 4 & 1 & 4 & 3 \\
$I_{8}$ & 12 & 4 & 3 & 0 & 12 & 6 & 1 & 7 & 5 \\
$I_{9}$ & 7 & 1 & 17 & 2 & 13 & 1 & 1 & 5 & 3 \\
$I_{10}$ & 4 & 6 & 4 & 6 & 3 & 13 & 0 & 2 & 12 \\
$I_{11}$ & 2 & 3 & 0 & 2 & 15 & 0 & 10 & 17 & 1 \\
$I_{12}$ & 31 & 6 & 4 & 1 & 3 & 0 & 1 & 3 & 1 \\
$I_{13}$ & 0 & 10 & 13 & 2 & 5 & 6 & 7 & 4 & 3 \\
$I_{14}$ & 12 & 15 & 2 & 0 & 0 & 5 & 6 & 4 & 6 \\
$I_{15}$ & 4 & 24 & 5 & 1 & 1 & 0 & 7 & 3 & 5 \\
$I_{16}$ & 0 & 5 & 3 & 14 & 7 & 9 & 2 & 6 & 4 \\
$I_{17}$ & 1 & 0 & 6 & 9 & 5 & 6 & 0 & 1 & 22 \\
$I_{18}$ & 2 & 4 & 0 & 1 & 0 & 2 & 12 & 5 & 24 \\
$I_{19}$ & 6 & 17 & 0 & 2 & 1 & 9 & 3 & 6 & 6 \\
\hline & & & & & & & & & \\
\end{tabular}


According to Eq. (1), the fuzzy index value of P1 is calculated. Similarly, the fuzzy index values of other five power PSS alternatives are calculated. The fuzzy index value matrix $\tilde{X}=\left[\tilde{x}_{s, i}\right]_{6 \times 19}$ is shown in Fig. 6 .

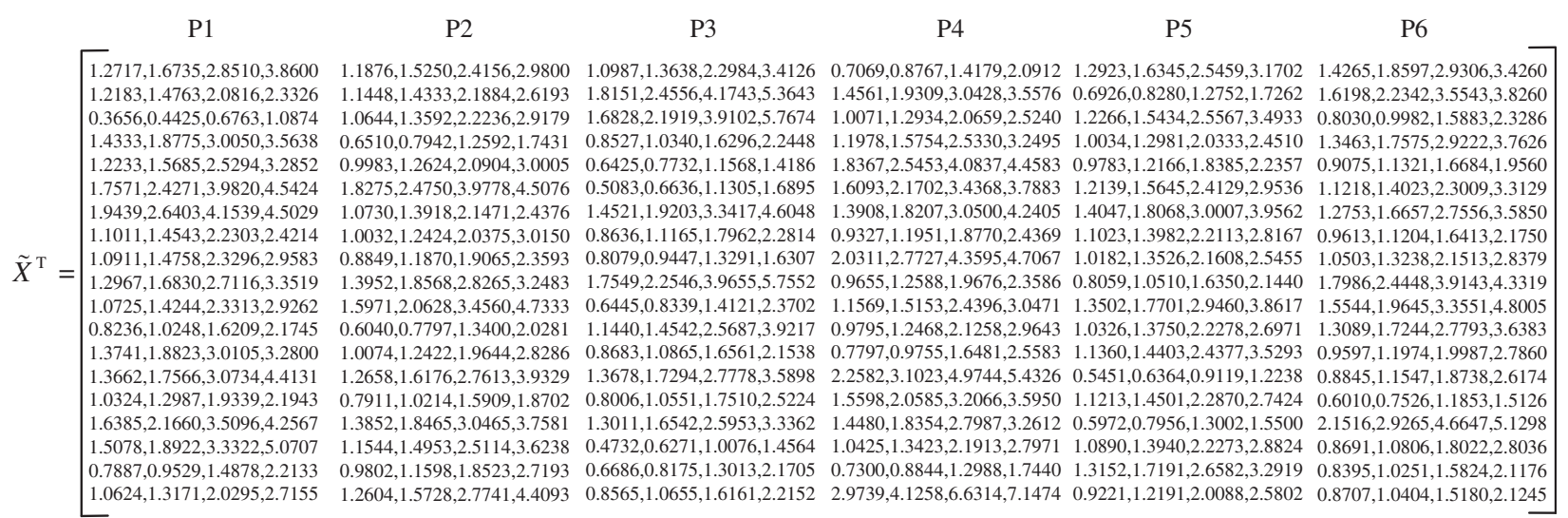

Figure 6: The fuzzy index value matrix $\tilde{X}=\left[\tilde{x}_{s, i}\right]_{6 \times 19}$

Then according to Eqs. (2)-(5), $\tilde{X}=\left[\tilde{x}_{s, i}\right]_{6 \times 19}$ is divided into four sub-matrices as $A=\left[a_{s, i}\right]_{6 \times 19}$, $B=\left[b_{s, i}\right]_{6 \times 19}, C=\left[c_{s, i}\right]_{6 \times 19}$ and $D=\left[d_{s, i}\right]_{6 \times 19}$. For example, $A=\left[a_{s, i}\right]_{6 \times 19}$ is shown in Fig. 7 .

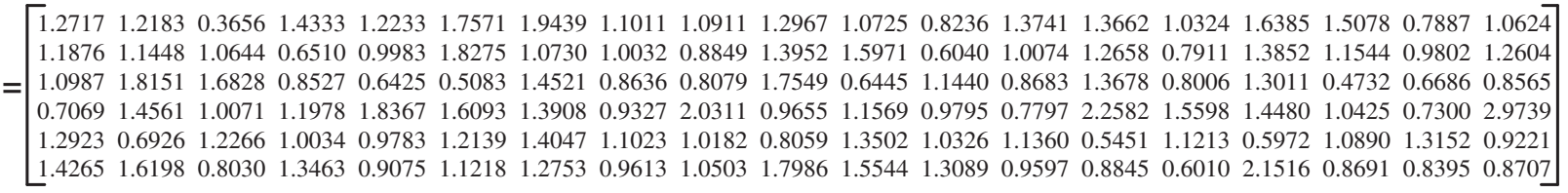

Figure 7: The sub-matrix $A=\left[a_{s, i}\right]_{6 \times 19}$

According to Eqs. (6) and (7), the positive ideal point and the negative ideal point in sub-matrix $A=\left[a_{s, i}\right]_{6 \times 19}$ are as follows:

$A^{+}=[1.4265,1.8151,1.6828,1.4333,1.8367,1.8275,1.9439,1.1023,2.0311,1.7986,1.5971,1.3089$,

$1.3741,2.2582,1.5598,2.1516,1.5078,1.3152,2.9739]$.

$A^{-}=[0.7069,0.6926,0.3656,0.6510,0.6425,0.5083,1.0730,0.8636,0.8079,0.8059,0.6445,0.6040$,

$0.7797,0.5451,0.6010,0.5972,0.4732,0.6686,0.8565]$.

According to Eqs. (8) and (9), the distances from $A^{1}$ to positive ideal point $A^{+}$and negative ideal point $A^{-}$are obtained as $\operatorname{dis} A^{1,+}=3.0677$ and $\operatorname{dis} A^{1,-}=2.8101$, respectively. Similarly, the distances from $B^{1}$ it to $B^{+}$and $B^{-}$are obtained as dis $B^{1,+}=4.4286$ and dis $B^{1,-}=3.8319$, respectively, the distances from $C^{1}$ it to $C^{+}$ and $C^{-}$are obtained as $\operatorname{dis} C^{1,+}=7.3943$ and $\operatorname{dis} C^{1,-}=6.3951$, respectively, and the distances from $D^{1}$ it to $D^{+}$and $D^{-}$are obtained as dis $D^{1,+}=8.5382$ dis $D^{1,+}=8.5382$ and dis $D^{1,-}=7.6926$, respectively.

Therefore, according to Eqs. (10) and (11) the distances in trapezoid fuzzy number form from $\tilde{X}^{1}$ to positive ideal point and negative ideal point are obtained as $\tilde{\delta}^{1,+}=(3.0677,4.4286,7.3943$, $8.5382) \tilde{\delta}^{1,+}=(3.0677,4.4286,7.3943,8.5382)$ and $\tilde{\delta}^{1,-}=(2.8101,3.8319,6.3951,7.6926)$ respectively. Through the gravity centre form transformation of trapezoid fuzzy number, according to Eqs. (12) and (13) $\tilde{\delta}^{1,+}$ and $\tilde{\delta}^{1,-}$ are converted into the real number form as $\tilde{\delta}^{1,+}=5.8518$ and 
$\tilde{\delta}^{1,-}=5.1896$, respectively. At last, according to Eq. (14) the closeness of P1 is obtained as $\phi^{1}=0.4700$. The detailed calculation data of six power PSS alternatives is shown in Table 3.

Table 3: The detailed calculation data of six power PSS alternatives

\begin{tabular}{|c|c|c|c|c|c|c|}
\hline & \multicolumn{2}{|c|}{ Distance in trapezoid fuzzy number form } & \multicolumn{2}{|c|}{ Distance in real number form } & \multirow[t]{2}{*}{ Closeness } & \multirow[t]{2}{*}{ Rank } \\
\hline & To positive ideal point & To negative ideal point & $\begin{array}{l}\text { To positive } \\
\text { ideal point }\end{array}$ & $\begin{array}{l}\text { To negative } \\
\text { ideal point }\end{array}$ & & \\
\hline $\mathrm{P} 1$ & $\begin{array}{l}(3.0677,4.4286 \\
7.3943,8.5382)\end{array}$ & $\begin{array}{l}(2.8101,3.8319 \\
6.3951,7.6926)\end{array}$ & 5.8518 & 5.1896 & 0.4700 & 2 \\
\hline $\mathrm{P} 2$ & $\begin{array}{l}(3.2274,4.6766 \\
7.4128,7.7608)\end{array}$ & $\begin{array}{l}(2.4543,3.2782 \\
5.4927,6.8621)\end{array}$ & 5.7467 & 4.5369 & 0.4412 & 3 \\
\hline P3 & $\begin{array}{l}(3.8292,5.4677 \\
8.8714,9.1701)\end{array}$ & $\begin{array}{l}(2.3969,3.1974 \\
5.8014,8.2745)\end{array}$ & 6.8099 & 4.9713 & 0.4220 & 5 \\
\hline P4 & $\begin{array}{l}(1.9861,2.8140 \\
4.7721,6.7630)\end{array}$ & $\begin{array}{l}(3.9181,5.5786 \\
9.0987,9.3628)\end{array}$ & 4.1243 & 6.9646 & 0.6281 & 1 \\
\hline P5 & $\begin{array}{l}(3.8998,5.5498 \\
9.0873,10.2724)\end{array}$ & $\begin{array}{l}(1.9777,2.6140 \\
4.2210,4.8977)\end{array}$ & 7.1913 & 3.4285 & 0.3228 & 6 \\
\hline P6 & $\begin{array}{l}(3.4128,4.9431, \\
8.1242,8.6058)\end{array}$ & $\begin{array}{l}(2.7692,3.7809, \\
6.1547,6.9212) \\
\end{array}$ & 6.2505 & 4.9009 & 0.4395 & 4 \\
\hline
\end{tabular}

According to the arranging rule of TOPSIS, six power PSS alternatives are arranged as $\mathrm{P} 4>\mathrm{P} 1>\mathrm{P} 2>$ P6 > P3 > P5. P4 is the best power PSS alternative.

In order to verify the feasibility of the proposed fuzzy-TOPSIS method and the advanced nature compared with other related methods, the calculation results of the proposed fuzzy-TOPSIS are compared with those of other related methods (TOPSIS [18], improved TOPSIS based on vertical distance [26] and improved TOPSIS based on angle measurement [27]) as shown in Fig. 8.

As shown Fig. 8, the calculation results of the proposed fuzzy-TOPSIS and TOPSIS are same, so the correctness of the proposed method can be verified. Because it has been verified that TOPSIS has obvious shortcomings, it is not recommended in many decision-making scenarios. The general trend of the calculation results of four methods is mainly consistent, in which P4 and P1 are the top two power PSS alternatives while P3 and P5 are the last two power PSS alternatives. However, by improved TOPSIS based on vertical distance [26] the closeness value of P2 and P6 are 0.5098 and 0.5439 (Fig. 8), which is contradicts other three methods. By improved TOPSIS based on angle measurement [27] the closeness of P3 and P6 are equal (0.5003 in Fig. 8) and the ranking of them cannot be implemented. As can be seen, improved TOPSIS based on vertical distance [26] and improved TOPSIS based on angle measurement [27] cannot satisfy the sorting decision-making requirements in some special cases. According to Fig. 8, the proposed fuzzy-TOSIS method can overcome the shortcomings of improved TOPSIS based on vertical distance [26] and improved TOPSIS based on angle measurement [27]. 


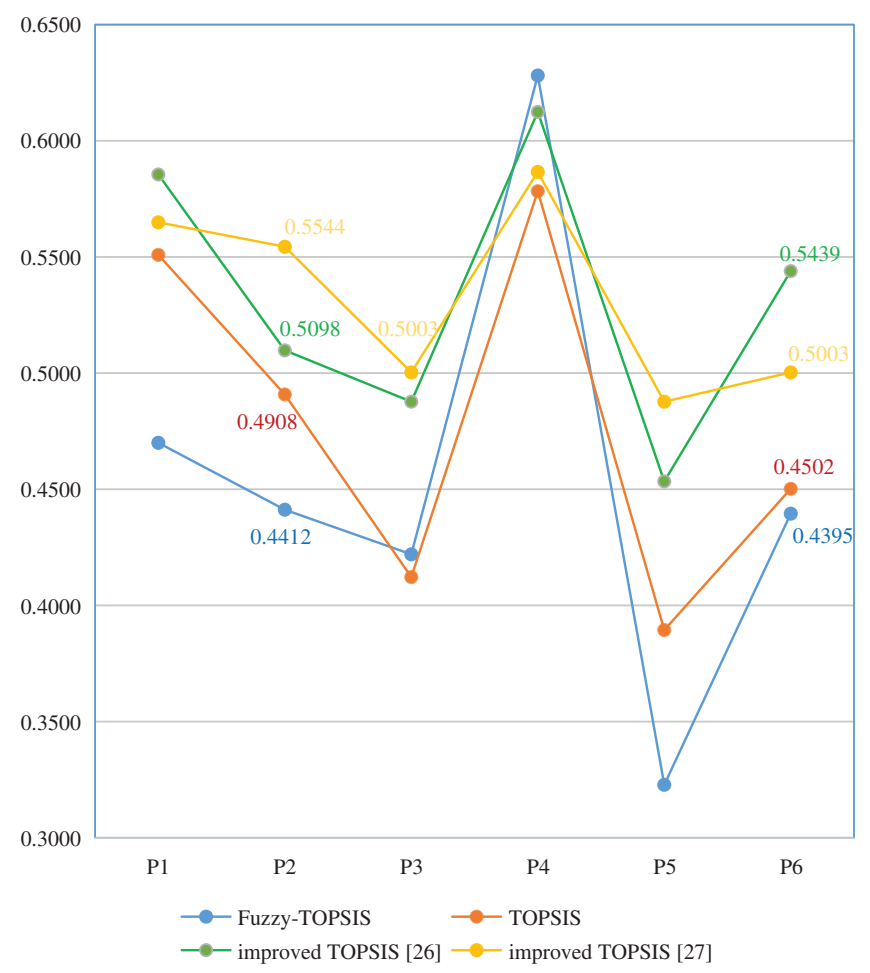

Figure 8: The calculation results

\section{Conclusions}

Power PSS is an important way for the combination of industrial electric products and electric energy services to meet the diversified needs of users and improve the competitiveness of enterprises. The design scheme evaluation of power PSS is a complex decision-making problem, involving two levels: multiattribute index evaluation and group collaborative evaluation. This paper aims at the worth-discussed problems in the existing research and proposes a big data driven framework for power PSS evaluation. The feasibility and effectiveness of proposed power PSS evaluation framework are proved by the case in a power enterprise. Through analysis and comparison with other related methods, it is proved that the calculation results is trustable and the big data driven framework for power PSS evaluation proposed in this paper can overcome the shortcomings of the existing methods and accurately select the best power PSS alternative. The index system based on big data from stakeholder comments is more suitable for practical decision-making scenarios, and can improve the rationality and authenticity of decision-making. The limitation of this paper is mainly that the indexes of power PSS evaluation are not completely independent but related. In future the theory of complex networks or analytic network process (ANP) will be used for reference to build index network model and determine the index weight in future research. In addition, fuzzy sets, fuzzy rough sets, vague sets, intuitionistic fuzzy sets and other uncertain information processing methods in artificial intelligence can be introduced into the framework of this paper.

Funding Statement: This study is supported by the Teaching and Research Fund of Ningbo University (Grant No. JYXMXYB202000).

Conflicts of Interest: The author declares that they have no conflicts of interest to report regarding the present study. 


\section{References}

1. Emili, S., Ceschin, F., Harrison, D. (2016). Product-service system applied to distributed renewable energy: A classification system, 15 archetypal models and a strategic design tool. Energy for Sustainable Development, 32(3), 71-98. DOI 10.1016/j.esd.2016.03.004.

2. Bacchetti, E. (2017). A design approach with method and tools to support SMEs in designing and implementing distributed renewable energy (DRE) solutions based on sustainable product-service system (S.PSS). 9th CIRP Industrial Product/Service-Systems (IPSS) Conference-Circular Perspectives on Product/Service-Systems, vol. 64, pp. 229-234. Copenhagen, Denmark.

3. Vezzoli, C., Ceschin, F., Diehl, J. C. (2015). Sustainable product-service system design applied to distributed renewable energy fostering the goal of sustainable energy for all. Journal of Cleaner Production, 97(4), 134136. DOI 10.1016/j.jclepro.2015.02.069.

4. Mourtzis, D., Boli, N., Alexopoulos, K., Róycki, D. (2018). A framework of energy services: From traditional contracts to product-service system (PSS). 25th CIRP Life Cycle Engineering (LCE) Conference, pp. 746-751. Copenhagen, Denmark.

5. Zhou, C., Li, T. (2019). Research on liquid metal energy storage battery equalization management system in power PSS. 11th CIRP Conference on Industrial Product-Service Systems, pp. 547-551. Zhuhai \& Hongkong, China.

6. Cheng, M., Luo, Q., Cui, Z. (2019). Research on total supply capability of distribution network based on power product service system. 11th CIRP Conference on Industrial Product-Service Systems, pp. 434-439. Zhuhai \& Hongkong, China.

7. Alfian, G., Rhee, J., Yoon, B. (2014). A simulation tool for prioritizing product-service system (PSS) models in a car sharing service. Computers \& Industrial Engineering, 70(1), 59-74. DOI 10.1016/j.cie.2014.01.007.

8. Chou, C., Chen, C., Conley, C. (2015). An approach to assessing sustainable product-service systems. Journal of Cleaner Production, 86(3), 277-284. DOI 10.1016/j.jclepro.2014.08.059.

9. Xia, Y. (2014). Performance comprehensive evaluation of composite earth pressure balanced shield machine cutter head. Journal of Mechanical Engineering, 50(21), 1-9. DOI 10.3901/JME.2014.21.001.

10. Wang, X., Durugbo, C. (2013). Analysing network uncertainty for industrial product-service delivery: A hybrid fuzzy approach. Expert System Application, 40(11), 4621-4636. DOI 10.1016/j.eswa.2013.01.062.

11. Fang, H., Tan, J., Yin, G., Li, Z. (2009). Design scheme evaluation based on improved uncertain-language multiattribute decision-making method. Computer Integrated Manufacturing Systems, 15(7), 1257-1261. DOI 10.13196/j.cims.2009.07.11.fangh.019.

12. Chen, D., Chu, X., Feng, T., Li, Y., Zuo, G. (2014). Product-service system evaluation based on information axiom in hybrid uncertain environment. Computer Integrated Manufacturing Systems, 20(8), 2071-2078. DOI 10.13196/ j.cims.2014.08.chendongping.2071.8.20140829.

13. Zuo, G., Chu, X., Chen, D., Li, Y., Feng, T. (2015). Product service system optimal selection based on intuitionistic fuzzy information axiom. Computer Integrated Manufacturing Systems, 21(4), 1134-1141. DOI 10.13196/j. cims.2015.04.028.

14. Tijs, V., van Veenstra, A. (2018). Governance of big data collaborations: How to balance regulatory compliance and disruptive innovation. Technological Forecasting \& Social Change, 129, 330-338. DOI 10.1016/j. techfore.2017.09.040.

15. Zdemir, V., Dove, E., Gürsoy, U. (2017). Personalized medicine beyond genomics: Alternative futures in big dataproteomics, environtome and the social proteome. Journal of Neural Transmission, 124(1), 25-32. DOI 10.1007/ s00702-015-1489-y.

16. Cai, X., Guo, D., Wang, T. (2011). The application of network and data mining to enterprises' financial competitive intelligence. Technology \& Innovation Management, 32(5), 561-564. DOI 10.14090/j.cnki.jscx.2011.05.029.

17. Zhang, H. (2020). Design of e-government user behavior feature extraction system based on data mining. Computing Technology and Automation, 39(3), 125-129. DOI 10.16339/j.cnki.jsjsyzdh.202003025.

18. Li, L., Hang, J., Gao, Y., Mu, C. (2017). Using an integrated group decision method based on SVM, TFN-RS-AHP, and TOPSIS-CD for cloud service supplier selection. Mathematical Problems in Engineering, 2017(11), 1-15. DOI 10.1155/2017/8513652. 
19. Grag, C. P., Sharma, A. (2020). Sustainable outsourcing partner selection and evaluation using an integrated BWM-VIKOR framework. Environment Development and Sustainability, 22(2), 1529-1557. DOI 10.1007/ s10668-018-0261-5.

20. Ostovari, Y., Honarbakhsh, A., Sangoony, H., Zolfaghari, F., Maleki, K. et al. (2019). GIS and multi-criteria decision-making analysis assessment of land suitability for rapeseed farming in calcareous soils of semi-arid regions. Ecological Indicators, 103(4), 479-487. DOI 10.1016/j.ecolind.2019.04.051.

21. Philip, C., Zhang, C. Y. (2014). Data-intensive applications, challenges, techniques and technologies: A survey on Big Data. Information Sciences, 275(11), 314-347. DOI 10.1016/j.ins.2014.01.015.

22. Gandomi, A., Haider, M. (2015). Beyond the hype, big data concepts, methods, and analytics. International Journal of Information Management, 35(2), 137-144. DOI 10.1016/j.ijinfomgt.2014.10.007.

23. Wang, H., Xu, Z. S., Fujita, H., Liu, S. S. (2016). Towards felicitous decision making, an overview on challenges and trends of big data. Information Sciences, 367, 747-765. DOI 10.1016/j.ins.2016.07.007.

24. Duan, Y., Edwards, J. S., Dwivedi, Y. K. (2019). Artificial intelligence for decision making in the era of big dataevolution, challenges and research agenda. International Journal of Information Management, 48(3), 63-71. DOI 10.1016/j.ijinfomgt.2019.01.021.

25. Acharya, A., Singh, S. K., Pereira, V., Singh, P. (2018). Big data, knowledge co-creation and decision making in fashion industry. International Journal of Information Management, 42(3-4), 90-101. DOI 10.1016/j. ijinfomgt.2018.06.008.

26. Tian, X., Li, C., Cao, Z., Liu, S., Wang, Y. (2020). Evaluation on water resources carrying capacity in western mining areas based on TOPSIS method. Mining Research and Development, 40(9), 170-175. DOI 10.13827/j. cnki.kyyk.2020.09.032.

27. Feng, X., Bai, Z., Zhan, L., Xie, Y., Li, B. (2019). Comparative research on evaluation methods of comprehensive production effect of greenhouse tomato based on entropy weight multi-attribute decision. Journal of Shenyang Agricultural University, 50(4), 445-453. DOI 10.3969/j.issn.1000-1700.2019.04.009. 